\title{
Non-vitamin K antagonist oral anticoagulants in patients with atrial fibrillation and colorectal cancer: a single-center experience
}

\author{
Konrad Stępień1,2, Karol Nowak ${ }^{1,2}$, Jarosław Zalewski ${ }^{1,2}$, Anetta Undas ${ }^{3,4}$ \\ 1 Department of Coronary Artery Disease and Heart Failure, Institute of Cardiology, Jagiellonian University Medical College, Kraków, Poland \\ 2 John Paul II Hospital, Kraków, Poland \\ 3 Department of Experimental Cardiac Surgery, Anesthesiology and Cardiology, Institute of Cardiology, Jagiellonian University Medical College, Kraków, Poland \\ 4 Krakow Center for Medical Research and Technology, John Paul II Hospital, Kraków, Poland
}

Correspondence to: Jarosław Zalewski, MD, PhD, Department of Coronary Artery Disease and Heart Failure, Institute of Cardiology, Jagiellonian University Medical College, ul. Prądnicka 80 , 31-202 Kraków, Poland, phone: +48126143004 email: jzalews@szpitaljp2.krakow.pl Received: October 6, 2019. Revision accepted: October 29, 2019. Published online: October 30, 2019. Kardiol Pol. 2019; 77 (12): 1186-1189 doi:10.33963/KP.15042 Copyright by the Author(s), 2019
Introduction Atrial fibrillation (AF) is the most common sustained cardiac arrhythmia observed in patients with cancer. A recent meta-analysis has shown that non-vitamin $\mathrm{K}$ antagonist oral anticoagulants (NOACs) used in AF patients with cancer reduce the risk of stroke or systemic embolism by $48 \%$ and intracranial or gastrointestinal bleedings by $35 \%$ as compared with warfarin. ${ }^{1}$ In patients with cancer-associated thrombosis, extended treatment with NOACs is associated with similar effectiveness and safety as low-molecular-weight heparins. ${ }^{2}$ However, there are limited data on the use of NOACs in patients with $\mathrm{AF}$ and specific types of cancer. ${ }^{1,3}$ Therefore, we sought to investigate the effectiveness and safety of NOACs in patients with AF and colorectal cancer.

Methods In this cohort study, we enrolled 44 consecutive ambulatory patients with active colorectal cancer and documented AF, who were referred to our center for further diagnostic workup between January 2013 to January 2017. Patients with colorectal cancer with life expectancy longer than 1 year who received chemotherapy, were diagnosed within the previous 6 months, or had recurrent or metastatic cancer were eligible. All patients refused to be treated with warfarin or heparins on a long-term basis. We excluded patients with a history of serious gastrointestinal or intracranial bleeding, hemoglobin levels lower than $9 \mathrm{~g} / \mathrm{dl}$, thrombocytopenia (platelet count, $<50 \times 10^{3} / \mu \mathrm{l}$ ), stage 4 or 5 chronic kidney disease, significant valvular disease, any valve prosthesis, acute coronary syndrome or ischemic stroke within the previous 6 months, or potent drug-drug interactions with anticancer agents (which are listed by Steffel et $\mathrm{al}^{3}$ ).

Anemia was recognized if hemoglobin levels were lower than $12 \mathrm{~g} / \mathrm{dl}$ in women and lower than $13 \mathrm{~g} / \mathrm{dl}$ in men. Thrombocytopenia was defined as a platelet count of less than $100 \times 10^{3} / \mu 1 .{ }^{4,5}$ Renal failure was diagnosed when creatinine clearance was below $60 \mathrm{ml} / \mathrm{min}$. The study protocol was approved by the Ethics Committee of Jagiellonian University (Kraków, Poland). All patients gave written informed consent to participate in the study.

Follow-up The follow-up started at the initiation of anticoagulation with a NOAC. Arterial and venous thromboembolic episodes as well as death were recorded based on medical records and history taken at clinic visits or by phone calls. Following stroke or thrombosis, patients received heparins at therapeutic doses and most of them continued parenteral anticoagulation. Major and clinically relevant nonmajor bleedings as well as withdrawal of NOAC treatment were also recorded. ${ }^{6}$

Statistical analysis Statistical analysis was performed with the Statistica 12.5 software (StatSoft, Tulsa, Oklahoma, United States). Continuous variables were expressed as median (interquartile range) and categorical variables as number (percentage), as appropriate. Continuous variables were compared with 
the Mann-Whitney test. Categorical variables were analyzed by the $\chi^{2}$ test or Fisher exact test. The Cox proportional hazard regression was used to determine independent predictors of survival free of thromboembolic events. A 2-sided $P$ of less than 0.05 was considered significant.

RESULTS The characteristics of the study group are shown in TABLE 1. Most patients had permanent $\mathrm{AF}$. The median time since cancer diagnosis to NOAC initiation was 6 months. The majority of patients received rivaroxaban. In this subgroup, the prevalence of renal failure was lower as compared with patients on dabigatran ( $15 \%$ vs $64 \% ; P=0.02$ ). Patients on apixaban were older compared with the dabigatran group (70 years vs 59 years; $P<0.001)$. Patients receiving a reduced dose of NOAC ( $n=20,45.5 \%$ ) more often had renal failure, prior stroke, and prior major bleeding compared with the remaining patients (TABLE1).

Within the median follow-up of 28.5 months, 26 patients died (59.1\%, 23.6\%/year). The overall NOAC withdrawal rate was $34.1 \%$ (16\%/year). Ischemic stroke or transient ischemic attack occurred in 5 patients $(11.4 \%, 4.9 \% /$ year) with a median $\mathrm{CHA}_{2} \mathrm{DS}_{2}$-VASc of 1 at a mean age of 68 years (median time since NOAC initiation, 15 months), including 1 patient on dabigatran (110 mg twice daily), 2 patients on rivaroxaban (15 mg once daily), and 2 patients on apixaban (2.5 mg twice daily). Two of these patients had prior ischemic stroke or transient ischemic attack before NOAC initiation. Two patients on apixaban (2.5 mg twice daily) experienced deep vein thrombosis (4.5\%, $1.9 \%$ /year), without symptomatic pulmonary embolism on

TABLE 1 Baseline characteristics and clinical outcomes of the studied patients (continued on the next page)

\begin{tabular}{|c|c|c|c|c|}
\hline \multicolumn{2}{|l|}{ Parameter } & $\begin{array}{l}\text { All patients } \\
\quad(n=44)\end{array}$ & $\begin{array}{l}\text { Full dose of NOAC } \\
(n=24)\end{array}$ & $\begin{array}{l}\text { Reduced dose of NOAC } \\
(n=20)\end{array}$ \\
\hline \multicolumn{2}{|l|}{ Age, y } & $67(60.5-70)$ & $67.5(62-70)$ & $63(59-73)$ \\
\hline \multicolumn{2}{|l|}{ Male sex } & $17(38.6)$ & $10(41.7)$ & $7(35)$ \\
\hline \multicolumn{2}{|c|}{ Body mass index, $\mathrm{kg} / \mathrm{m}^{2}$} & $27(24.3-31.3)$ & $27(24.5-31.4)$ & $26.8(22.9-31.1)$ \\
\hline \multicolumn{2}{|c|}{ Active smoking } & $18(40.9)$ & $8(33.3)$ & $10(50)$ \\
\hline \multicolumn{2}{|c|}{ Hypertension } & $14(31.8)$ & $9(37.5)$ & $5(25)$ \\
\hline \multicolumn{2}{|c|}{ Diabetes mellitus } & $2(4.5)$ & 0 & $2(10)$ \\
\hline \multicolumn{2}{|l|}{ Renal failure } & $13(29.5)$ & $2(8.3)$ & $11(55)^{\mathrm{a}}$ \\
\hline \multicolumn{2}{|c|}{ Glomerular filtration rate, $\mathrm{ml} / \mathrm{min}$} & $68(55-75)$ & $72.5(66.5-82.5)$ & $55.5(45-67.5)^{b}$ \\
\hline \multicolumn{2}{|l|}{ Anemia } & $27(61.4)$ & $17(70.8)$ & $10(50)$ \\
\hline \multicolumn{2}{|c|}{ Hemoglobin, g/dl } & $12.1(10.9-13.1)$ & $11.7(10.7-12.9)$ & $12.5(11.3-13.6)$ \\
\hline \multicolumn{2}{|c|}{ Thrombocytopenia } & $14(31.8)$ & $8(33.3)$ & $6(30)$ \\
\hline \multicolumn{2}{|c|}{ Platelet count, $\times 10^{3} / \mu \mathrm{l}$} & $120(93-151)$ & $122(95-155)$ & $107(90-148)$ \\
\hline \multicolumn{2}{|l|}{ Prior stroke } & $5(11.4)$ & 0 & $5(25)^{c}$ \\
\hline \multicolumn{2}{|c|}{ Prior myocardial infarction } & $3(6.8)$ & $1(4.2)$ & $2(10)$ \\
\hline \multicolumn{2}{|c|}{ Prior bleeding } & $12(27.3)$ & $2(8.3)$ & $10(50)^{d}$ \\
\hline \multicolumn{2}{|c|}{ History of peptic ulcer } & $11(25)$ & $5(20.8)$ & $6(30)$ \\
\hline \multicolumn{2}{|c|}{ Time since AF diagnosis, mo } & $23(18.5-45)$ & $24(19-47)$ & $22.5(17-42)$ \\
\hline \multicolumn{2}{|c|}{$\mathrm{CHA}_{2} \mathrm{DS}_{2}$-VASc score $\geq 2$} & $27(61.4)$ & $13(54.2)$ & $14(70)$ \\
\hline \multicolumn{2}{|c|}{$\mathrm{CHA}_{2} \mathrm{DS}_{2}$-VASc score, 0} & $5(11.4)$ & $3(12.5)$ & $2(10)$ \\
\hline \multicolumn{2}{|c|}{ HAS-BLED score $\geq 3$} & $16(36.4)$ & $10(41.7)$ & $6(30)$ \\
\hline \multirow[t]{3}{*}{ Types of AF } & Permanent & $31(70.5)$ & $17(70.8)$ & $14(70)$ \\
\hline & Persistent & $10(22.7)$ & $5(20.8)$ & $5(25)$ \\
\hline & Paroxysmal & $3(6.8)$ & $2(8.3)$ & $1(5)$ \\
\hline \multicolumn{2}{|c|}{ Time since cancer diagnosis, mo } & $6(5-7.5)$ & $6(5-7)$ & $5.5(5-9)$ \\
\hline \multicolumn{2}{|c|}{ Prior surgical treatment } & $27(61.4)$ & $13(54.2)$ & $14(70)$ \\
\hline \multicolumn{2}{|c|}{ Palliative surgery } & $9(20.5)$ & $6(25)$ & $3(15)$ \\
\hline \multicolumn{2}{|c|}{ Metastatic disease } & $23(52.3)$ & $15(62.5)$ & $8(40)$ \\
\hline
\end{tabular}


TABLE 1 Baseline characteristics and clinical outcomes of the studied patients (continued from the previous page)

\begin{tabular}{|c|c|c|c|c|}
\hline \multicolumn{2}{|l|}{ Parameter } & $\begin{array}{l}\text { All patients } \\
(n=44)\end{array}$ & $\begin{array}{l}\text { Full dose of NOAC } \\
(n=24)\end{array}$ & $\begin{array}{l}\text { Reduced dose of NOAC } \\
(n=20)\end{array}$ \\
\hline \multicolumn{2}{|l|}{ Chemotherapy } & $30(68.2)$ & $17(70.8)$ & $13(65)$ \\
\hline \multirow[t]{3}{*}{ Antithrombotic treatment } & Rivaroxaban & $20(45.5)$ & $13(54.2)$ & $7(35)$ \\
\hline & Apixaban & $13(29.5)$ & $6(25)$ & $7(35)$ \\
\hline & Dabigatran & $11(25)$ & $5(20.8)$ & $6(30)$ \\
\hline \multicolumn{2}{|c|}{ NOAC initiation within 6 months since cancer diagnosis } & $16(36.4)$ & $6(25)$ & $10(50)$ \\
\hline \multicolumn{5}{|l|}{ Follow-up } \\
\hline \multicolumn{2}{|l|}{ Follow-up, mo } & $28.5(25-35.5)$ & $25.5(24-34.5)$ & $30.5(26.5-37)$ \\
\hline \multicolumn{2}{|c|}{ NOAC withdrawal during follow-up } & $15(34.1)$ & $11(45.8)$ & $4(20)$ \\
\hline \multicolumn{2}{|c|}{ Time to NOAC withdrawal, mo } & $24(20.5-32.5)$ & $23(20-33)$ & $30(25-32)$ \\
\hline \multirow[t]{7}{*}{ Clinical outcomes } & Stroke / transient ischemic attack & $5(11.4)$ & 0 & $5(25)$ \\
\hline & New deep vein thrombosis & $2(4.5)$ & 0 & $2(10)$ \\
\hline & Major bleeding & $2(4.5)$ & $2(8.3)$ & 0 \\
\hline & Clinically relevant nonmajor bleeding & $5(11.4)$ & $2(8.3)$ & $3(15)$ \\
\hline & Gastrointestinal bleeding & $3(6.8)$ & $1(4.2)$ & $2(10)$ \\
\hline & Death & $26(59.1)$ & $17(70.8)$ & $9(45)$ \\
\hline & Cancer progression as a cause of death & $22(50)$ & $15(62.5)$ & $7(35)$ \\
\hline
\end{tabular}

Data are shown as number (percentage) or median (interquartile range).

a $P=0.001 ; \quad$ b $P<0.001 ; \quad$ c $P=0.014 ; \quad$ d $P=0.005$ for full vs reduced NOAC dose

Abbreviations: $\mathrm{AF}$, atrial fibrillation; $\mathrm{CHA}_{2} \mathrm{DS}_{2}-\mathrm{VASc}$, congestive heart failure, hypertension, age $\geq 75$ years, diabetes mellitus, history of stroke or thromboembolism, vascular disease, age 65 to 74 years, female sex; HAS-BLED, hypertension, abnormal liver function, history of stroke or thromboembolism, history of bleeding, age $\geq 65$ years, use of nonsteroidal anti-inflammatory drugs, and alcohol abuse; NOAC, non-vitamin K antagonist oral anticoagulant

computed tomography angiography. Two major gastrointestinal bleedings occurred in patients on full-dose apixaban and rivaroxaban 4 and 7 months since NOAC initiation, respectively. Clinically relevant nonmajor bleedings were reported in 5 patients $(11.4 \%, 2 \% /$ year), with a comparable distribution between the 2 NOAC regimens. Of these, 3 events (6.8\%) were gastrointestinal bleedings requiring hospitalization. Major or clinically relevant nonmajor bleeds were not associated with thrombocytopenia; however, 2 patients had both metastatic disease and HAS-BLED score equal to or higher than 3 . No death was related to any recorded hemorrhage or stroke. After adjustment for metastatic disease, the use of a reduced-dose NOAC independently predicted thromboembolic events (hazard ratio, 2.08; 95\% CI, 1.05-4.17; $P=0.04$ ) but not death.

DISCUSSION Our study showed that the use of NOACs in patients with AF and colorectal cancer could be an effective and safe option of anticoagulant therapy. We found that the use of NOACs was associated with a low incidence of thromboembolism and an acceptable risk of bleeding, without any association with the $\mathrm{CHA}_{2} \mathrm{DS}_{2}$-VASc or HASBLED scores, which is in line with other reports. ${ }^{7,8}$ Recently, it has been recommended that NOACs should be preferred over warfarin in cancer patients receiving chemotherapy with newly diagnosed AF except for patients with gastrointestinal cancer, based on data from trials on rivaroxaban and edoxaban in patients with venous thromboembolism. ${ }^{9}$ Our study showed that the use of NOACs was not associated with high risk of gastrointestinal bleeds, at least in patients with colorectal cancer after surgery and the first-line anticancer therapy.

This is probably the largest study that focused on patients with AF and colorectal cancer receiving NOACs. Malavasi et $\mathrm{al}^{10}$ reported data from 394 cancer patients with AF, including 69 individuals with gastrointestinal cancer, of whom only $40 \%$ received antithrombotic therapy, including 3 patients on NOACs. In a Danish population-based cohort study, the absolute risks of thromboembolic or bleeding complications were similar in AF patients with and without cancer who redeemed prescription for vitamin K antagonists or NOACs. ${ }^{8}$

The current European Society of Cardiology guidelines recommend using NOACs at a reduced dose in patients with $\mathrm{AF}$ at high risk of gastrointestinal bleeding (class IIa). ${ }^{11}$ Such a regimen was used in almost half of our patients. However, 
lower doses were associated with high thromboembolic risk, suggesting that NOACs at a full dose may be preferable in cancer whenever possible. The assessment of NOAC concentrations and improved knowledge on anticoagulation in AF may help optimize anticoagulant therapy. ${ }^{12-14}$ Although the availability of idarucizumab might encourage physicians to prescribe dabigatran, ${ }^{15}$ it was the least commonly used drug in our cohort. The study was too small to assess the outcomes of different NOACs in cancer patients.

Our single-center experience suggests that the use of NOACs might be an attractive anticoagulation option in patients with $\mathrm{AF}$ and colorectal cancer.

\section{ARTICLE INFORMATION}

ACKNOWLEDGMENTS This work was supported by Jagiellonian University Medical College (N41/DBS/000184; to AU).

CONFLICT OF INTEREST AU received lecture honoraria from Bayer, Boehringer Ingelheim, Pfizer, and Sanofi-Aventis. The remaining authors have nothing to disclose in relation to this study.

OPEN ACCESS This is an Open Access article distributed under the terms of the Creative Commons Attribution-NonCommercial-NoDerivatives 4.0 International License (CC BY-NC-ND 4.0), allowing third parties to download articles and share them with others, provided the original work is properly cited not changed in any way, distributed under the same license, and used for noncommercial purposes only. For commercial use, please contact the journal office at kardiologiapolska@ptkardio.pl.

HOW TO CITE Stępień K, Nowak K, Zalewski J, Undas A. Non-vitamin K antagonist oral anticoagulants in patients with atrial fibrillation and colorectal cancer: a single-center experience. Kardiol Pol. 2019; 77: 1186-1189. doi:10.33963/ KP.15042

\section{REFERENCES}

1 Deng $Y$, Tong $Y$, Deng $Y$, et al. Non-vitamin $K$ antagonist oral anticoagulants versus warfarin in patients with cancer and atrial fibrillation: a systematic review and meta-analysis. J Am Heart Assoc. 2019; 8: e012540.

2 Stepien K, Nowak K, Zalewski J, et al. Extended treatment with non-vitamin $K$ antagonist oral anticoagulants versus low-molecular-weight heparins in cancer patients following venous thromboembolism. A pilot study. Vascul Pharmacol. 2019; 120: 106567.

3 Steffel J, Verhamme P, Potpara TS, et al. The 2018 European Heart Rhythm Association Practical Guide on the use of non-vitamin $\mathrm{K}$ antagonist oral anticoagulants in patients with atrial fibrillation. Eur Heart J. 2018; 39: 1330-1393.

4 Skorek P, Stępień K, Fila M, et al. Preoperative thrombocytosis in surgically treated patients with non-small cell lung cancer. Pol Arch Intern Med. 2018; 128: 512-517. 5 Janion-Sadowska A, Papuga-Szela E, Łukaszuk R, et al. Non-vitamin K antagonist oral anticoagulants in patients with atrial fibrillation and thrombocytopenia. J Cardiovasc Pharmacol. 2018; 72: 153-160.

6 Bryk AH, Łukaszuk R, Donicz P, et al. Efficacy and safety of apixaban in real-life patients at high bleeding risk. Pol Arch Intern Med. 2017; 127: 889-891.

7 Vedovati MC, Giustozzi M, Verdecchia P, at el. Patients with cancer and atrial fibrillation treated with DOACs: A prospective cohort study. Int J Cardiol. 2018; 269: 152-157.

8 Ording AG, Horváth-Puhó E, Adelborg K, et al. Thromboembolic and bleeding complications during oral anticoagulation therapy in cancer patients with atrial fibrillation: a Danish nationwide population-based cohort study. Cancer Med. 2017; 6: 1165-1172

9 Delluc A, Wang TF, Yap ES, et al. Anticoagulation of cancer patients with non-valvular atrial fibrillation receiving chemotherapy: Guidance from the SSC of the ISTH. J Thromb Haemost. 2019; 17: 1247-1252.

10 Malavasi VL, Fantecchi E, Gianolio L, et al. Atrial fibrillation in patients with active malignancy and use of anticoagulants: Under-prescription but no adverse impact on all-cause mortality. Eur J Intern Med. 2019; 59: 27-33.

11 Kirchhof P, Benussi S, Kotecha D, et al. 2016 ESC Guidelines for the management of atrial fibrillation developed in collaboration with EACTS. Eur J Cardiothorac Surg. 2016; 50: e1-e88.

12 Tripodi A, Braham S, Scimeca B, et al. How and when to measure anticoagulant effects of direct oral anticoagulants? Practical issues. Pol Arch Intern Med. 2018; $128: 379-385$

13 Konieczyńska M, Sobieraj E, Bryk AH, et al. Differences in knowledge among patients with atrial fibrillation receiving non-vitamin $\mathrm{K}$ antagonist oral anticoagulants and vitamin K antagonists. Kardiol Pol. 2018; 76: 1089-1096.
14 Bednarski J, Balsam P, Tymińska A, et al. District versus academic hospitals: differences in the clinical characteristics of patients with atrial fibrillation without valvular heart disease treated with oral anticoagulants. Pol Arch Intern Med. 2018; 128: 274-279.

15 Pruszczyk P, Tomaszuk-Kazberuk A, Słowik A, et al. Management of bleeding or urgent interventions in patients treated with direct oral anticoagulants: 2017 recommendations for Poland. Pol Arch Intern Med. 2017; 127: 343-351. 